\title{
Physico-Chemical and Molecular Interactions in Sodium Dodecyl Sulfate+Acetamide, Formamide Aqueous Mixtures According to Dielectric Relaxation Spectroscopy Data at $303 \mathrm{~K}$
}

\author{
Thirunavukarasu Kalaivani ${ }^{1}$ (D), Subramanian Krishnan ${ }^{2}$ (D), Subramanian Nithiyanantham ${ }^{1,3, * \text { (D) }}$ \\ 1 Center for Material Science and Nano Devices, Department of Physics and Nanotechnology, SRM University, \\ Kattankulathur, Tamilnadu, India - 603203 \\ 2 Department of Physics, Annamalai University, Annamalainagar Tamilnadu, India - 608002 \\ 3 Post Graduate \& Research Department of Physics, (Ultrasonics/Bio-Physics Divisions), Thiru. Vi. Ka.Govt Arts and \\ Science College, Thiruvaur, Tamilnadu, India-610003.(Bharathidasan University Affiliation- Thiruchirapalli) \\ * Correspondence: s_nithu59@rediffmail.com; prof.nithiyanantham.s@tvkgovac.in;
}

Scopus Author ID 34768710400

Received: 11.10.2020; Revised: 12.01.2021; Accepted: 15.01.2021; Published: 20.01.2021

\begin{abstract}
Investigation of sodium dodecyl sulfate+acetamide, formamide aqueous mixtures of various concentrations has been performed by dielectric relaxation spectroscopy (TDR-time domain reflectometry) technique $303 \mathrm{~K}$. The relaxation times were determined through the Debye method and relative viscosities of solution. The linear increase of relative viscosity has the same increasing trend as dodecyl sulfate concentrations up to $80 \mathrm{mM}$. The superposition of relaxation time between water and micelle through the rotation phenomena, whereas inside the micelle by hydrophobic phenomena, is found and discussed in light of obtained results and justified.
\end{abstract}

Keywords: dielectric relaxation spectroscopy; time domain reflectometry; surfactant; SDS; acetamide; formamide.

(C) 2020 by the authors. This article is an open-access article distributed under the terms and conditions of the Creative Commons Attribution (CC BY) license (https://creativecommons.org/licenses/by/4.0/).

\section{Introduction}

In recent years, molecular interaction or ionic interaction, surfactant, and rheological behavior were analyzed through the physicochemical parameters. Dielectric spectroscopy is the most commonly employed method for investigating some type of fluids like supercooled liquids, amides, some complex fluids, etc., [1-3]. Surfactants are receiving more attention due to their specific and peculiar natures, such as a low critical micelle concentration $(\mathrm{cmc})$, high efficiency in reducing the surface tension, less chemical activity, and thermal stability. The strong intramolecular bonds and weak intermolecular interactions are used to analyze their nature [1-5].

The bases of molecular interaction are hydrogen bonding occurring between hydrogencontaining dipoles and electronegative element atoms. The Domain Spectroscopy (DS) technique gives information in a wide frequency range with dielectric information. Using this dielectric data, Prof. Cole developed this Cole- Cole technique to understand any surfactants' behavior; the thermodynamical parameters are widely used [6-10]. In the case of micelles surfactant solutions, the volume and heat capacity is useful for studying the changes in 
hydrophobic interactions leading to micellization or association and disassociation behavior [11].

A Debye-like relaxation studying liquids of a supramolecular and related type of liquids currently received a great deal of attention [11]. To understand the properties of hydrogenbonded systems, including water, macromolecules, and micelle, the systems' aggregations by the change or variation with related parameters partial molar volume, volume expansion coefficient, heat capacity, etc., [12]. Hence, order to analyze the micellization process is helpful in many cleaning and hygiene goods of aqueous solutions of anionic surfactant.

\section{Materials and Methods}

All Annular grade chemicals were purchased with a purity of $99 \%$ was used directly without further purification. The viscosity measurements were carried out through an Ostwald viscometer $(20 \mathrm{ml})$, and the density measurements were made using a standard pyknometer (5ml). All solutions were prepared in double-distilled deionized water within 1-2 $\mu \mathrm{s} \mathrm{cm}^{-1}$.

The dielectric measurements were made using Time Domain Reflectometry in the frequency range from $10 \mathrm{MHz}$ to $20 \mathrm{GHz}$ using an HP54750A sampling oscilloscope and HP54754A TDR plug-in-module. The sample was placed at the end of the coaxial line in a Standard Military Application (SMA) coaxial cell of $3.5 \mathrm{~mm}$ outer diameter and $1.35 \mathrm{~mm}$ effective pin length. The change in the pulse shape is monitored by a sampling oscilloscope and recorded with a time of 5ns, reflected from the sample placed in the cell. The reflection pulse with $\mathrm{Rx}(\mathrm{t})$ and without sample $\mathrm{R}_{1}(\mathrm{t})$ was digitized in 1024 points and transferred to a computer through GPIB, and the temperature was maintained with a constant water bath $\left( \pm 1^{\circ} \mathrm{C}\right)$ [13-14]. The values of $p(\omega)$ and $q(\omega)$ is obtained through a Fourier transform of $\left\{R_{1}(t)-R_{x}(t)\right\}$ and $\left\{R_{1}(t)+R_{x}(t)\right\}$ thorough the required Spectra $\rho^{*}(\omega)$ over the frequency range of $10 \mathrm{MHz}$ to $20 \mathrm{GHz}$ are obtained as,

$$
\rho^{*}(\omega)=\frac{c / j \omega d}{p(\omega) q(\omega)}
$$

Here, $\omega \mathrm{c}$ and d) the angular frequency, light velocity, and effective pin length. By applying a bilinear combination on the reflection coefficient, the result of complex spectra is obtained [15]. The experimental values $\varepsilon^{*}$ are fitted with Debye equation with $\varepsilon_{0}$ and $\tau$ as fitting parameters. A non-linear least-squares fit method was used [16]. Here, this $\varepsilon_{\infty}$ are considered as an adjustable parameter.

\section{Results and Discussion}

The complex dielectric permittivities of SDS solutions from 2 to $100 \mathrm{mM}$ with various additives were recorded at $303 \mathrm{~K}$, the values of $\varepsilon^{\prime}$ and $\varepsilon^{\prime \prime}$ were obtained from spectra. Density, static dielectric constant, and relative viscosity values of the SDS solution are presented in Table 1. The relaxation time $(\tau)$ is measured from the Debye method. The calculated values of the $\tau / \eta_{\mathrm{r}}$, the volume fraction, and the molar volume of the hydrated micelles with the activation energies for the Acetamide and Formamide with SDS are presented in Table 2.

The relative viscosity relates to the molar volume of hydrated micelle [17]. The functions of relaxation species in relation to its hydrodynamical volume belonging to the value of $\tau / \eta_{\mathrm{r}}$. From the Eyring's rate theory equations, due to dipolar rotation leads the free energy of activation $\left(\Delta \mathrm{F}_{\tau}\right)$ and viscous flow $\left(\Delta \mathrm{F}_{\eta}\right)$ was calculated from the following relations, 


$$
\begin{gathered}
\tau=\frac{h}{k T} \exp \left[\frac{\Delta F_{\tau}}{R T}\right] \\
\eta=\frac{N_{A} h}{V}\left[\frac{\Delta F_{\eta}}{R T}\right]
\end{gathered}
$$

Where $\mathrm{N}_{\mathrm{A}}$ and $\mathrm{V}$ are the Avogadro number and molar volume of the liquid. The relaxation time $\tau$ was observed in the frequency region $10 \mathrm{MHz}$ to $20 \mathrm{GHz}$.

\begin{tabular}{|c|c|c|c|c|c|c|c|c|c|c|c|}
\hline \multirow{2}{*}{ Acetamide } & Conc & Density & \multirow{2}{*}{$\varepsilon_{0}$} & \multirow{2}{*}{$\eta_{\rho}$} & $\tau$ & \multirow[b]{2}{*}{ Formamide } & \multirow{2}{*}{\begin{tabular}{|l|} 
Conc \\
$\mathbf{m M}$ \\
\end{tabular}} & \multirow{2}{*}{\begin{tabular}{|c|} 
Density \\
$\mathrm{kg} \mathrm{m}^{-3}$
\end{tabular}} & \multirow[t]{2}{*}{$\varepsilon_{0}$} & \multirow[t]{2}{*}{$\eta_{\rho}$} & \multirow{2}{*}{$\frac{\tau}{\text { ps }}$} \\
\hline & $\mathbf{m M}$ & $\mathrm{kg} \mathrm{m}^{-3}$ & & & ps & & & & & & \\
\hline \multirow[t]{8}{*}{0.05} & 2 & 994.3 & 77.14 & 1.001 & 14.09 & 0.05 & 2 & 998.2 & 77.26 & 1.002 & 14.02 \\
\hline & 4 & 996.1 & 78.02 & 1.002 & 15.36 & & 4 & 1002.5 & 78.32 & 1.004 & 15.14 \\
\hline & 6 & 998.7 & 79.36 & 1.003 & 16.48 & & 6 & 1010.6 & 79.45 & 1.008 & 16.32 \\
\hline & 10 & 999.6 & 80.58 & 1.004 & 18.03 & & 10 & 1013.2 & 80.62 & 1.018 & 17.86 \\
\hline & 30 & 1000.2 & 82.41 & 1.010 & 19.78 & & 30 & 1015.2 & 82.53 & 1.068 & 18.84 \\
\hline & 50 & 1008.2 & 83.31 & 1.026 & 20.32 & & 50 & 1017.4 & 83.44 & 1.092 & 19.99 \\
\hline & 80 & 1014.3 & 87.43 & 1.043 & 23.02 & & 80 & \begin{tabular}{|l|}
1019.2 \\
\end{tabular} & 87.51 & 1.108 & 22.84 \\
\hline & 100 & 1016.9 & 88.14 & 1.083 & 24.16 & & 100 & 1022.2 & 88.26 & 1.13 & 23.86 \\
\hline \multirow[t]{8}{*}{0.10} & 2 & 996.7 & 76.89 & 1.001 & 13.58 & 0.10 & 2 & 998.6 & 76.92 & 1.002 & 13.52 \\
\hline & 4 & 998.3 & 77.6 & 1.001 & 14.81 & & 4 & 1002.5 & 77.69 & 1.003 & 14.64 \\
\hline & 6 & 998.5 & 78.31 & 1.004 & 15.04 & & 6 & 1012.4 & 78.4 & 1.008 & 15.01 \\
\hline & 10 & 100.3 & 79.82 & 1.009 & 17.29 & & 10 & 1013.9 & 79.91 & 1.018 & 17.02 \\
\hline & 30 & 1008.3 & 81.89 & 1.016 & 19.48 & & 30 & 1015.8 & 81.92 & 1.068 & 19.32 \\
\hline & 50 & 1010.2 & 83.33 & 1.029 & 19.81 & & 50 & 1017.5 & 83.45 & 1.092 & 19.71 \\
\hline & 80 & 1015.1 & 87.41 & 1.056 & 21.71 & & 80 & \begin{tabular}{|l|}
1020.1 \\
\end{tabular} & 87.51 & 1.107 & 21.64 \\
\hline & 100 & 1017.8 & 88.12 & 1.074 & 22.22 & & 100 & \begin{tabular}{|l|}
1023.6 \\
\end{tabular} & 88.23 & 1.132 & 22.03 \\
\hline \multirow[t]{8}{*}{0.15} & 2 & 997.3 & 76.51 & 1.002 & 13.41 & 0.15 & 2 & 999.2 & 76.54 & 1.001 & 13.21 \\
\hline & 4 & 999.2 & 76.68 & 1.004 & 14.59 & & 4 & \begin{tabular}{|l|}
1002.5 \\
\end{tabular} & 76.71 & 1.002 & 14.04 \\
\hline & 6 & 1002.4 & 76.79 & 1.004 & 14.62 & & 6 & \begin{tabular}{|l|}
1012.8 \\
\end{tabular} & 76.83 & 1.007 & 14.39 \\
\hline & 10 & 1003.6 & 78.48 & 1.009 & 16.74 & & 10 & 1014.5 & 78.52 & 1.018 & 16.71 \\
\hline & 30 & 1009.2 & 80.13 & 1.013 & 18.46 & & 30 & 1016.2 & 80.16 & 1.067 & 18.21 \\
\hline & 50 & 1011.1 & 81.29 & 1.021 & 18.52 & & 50 & 1018.4 & 81.31 & 1.071 & 18.33 \\
\hline & 80 & 1016.3 & 84.06 & 1.058 & 20.73 & & 80 & 1021.2 & 84.11 & 1.106 & 20.42 \\
\hline & 100 & 1018.2 & 84.52 & 1.098 & 21.6 & & 100 & 1023.4 & 84.61 & 1.131 & 21.49 \\
\hline \multirow[t]{8}{*}{0.20} & 2 & 998.2 & 75.81 & 1.002 & 12.69 & 0.20 & 2 & 999.7 & 75.86 & 1.001 & 12.52 \\
\hline & 4 & 999.8 & 75.87 & 1.003 & 14.02 & & 4 & 1003.2 & 75.91 & 1.002 & 13.86 \\
\hline & 6 & 1002.9 & 76.46 & 1.007 & 14.24 & & 6 & \begin{tabular}{|l|}
1013.4 \\
\end{tabular} & 76.5 & 1.006 & 14.11 \\
\hline & 10 & 1004.1 & 77.83 & 1.018 & 15.86 & & 10 & 1015.6 & 77.86 & 1.017 & 15.72 \\
\hline & 30 & 1009.8 & 79.63 & 1.027 & 17.73 & & 30 & 1017.2 & 79.67 & 1.067 & 17.51 \\
\hline & 50 & 1012.3 & 80.72 & 1.048 & 17.92 & & 50 & 1019.5 & 80.78 & 1.091 & 17.63 \\
\hline & 80 & 1017.3 & 82.85 & 1.067 & 19.21 & & 80 & 1022.2 & 82.91 & 1.106 & 18.94 \\
\hline & 100 & 1018.8 & 83.32 & 1.078 & 20.29 & & 100 & 1024.6 & 83.41 & 1.132 & 20.03 \\
\hline
\end{tabular}

Table 1. Dielectric relaxation of aqueous SDS with Amides and related parameters at $303 \mathrm{~K}$.

The substances dissolve with the polar groups at the hydrocarbon/water interface of the micelle surface and thereby promote the formation of micellar growth. The dielectric properties of water were not evenly disturbed in the present analysis by the addition of additives except for a slight decrease in static permittivity.

The decreasing mobility with an increasing relative viscosity of micelle shows a similar trend as Guth et al. [18], and the authors have calculated the molar volume of the hydrated micelles using the Guth and Simha equation [18-19].

$$
\eta_{r}=1+2.5 \phi_{m}+14.1 \phi_{m}^{2}
$$

where $\phi_{\mathrm{m}}$ is the volume fraction of the hydrated micelles $[17,18]$. 
Table 2. Activation energies for dielectric and other parameters for SDS micellar solutions at $303 \mathrm{~K}$.

\begin{tabular}{|c|c|c|c|c|c|c|}
\hline Acetamid & Conc & $\tau / \eta_{\rho}$ & $\phi_{\mu}$ & $\mathrm{V}_{\mathrm{h}}(\mathrm{ml})$ & $\Delta \mathrm{F}_{\tau}$ & $\Delta \mathrm{F}_{\eta}$ \\
\hline $\mathrm{M} / \mathrm{l}$ & $\mathrm{mM}$ & ps & & $\mathrm{x} 10^{-20}$ & $\mathrm{~kJ} \mathrm{~mol}^{-1}$ & $\mathrm{~kJ} \mathrm{~mol}^{-1}$ \\
\hline \multirow{8}{*}{05} & 2 & 14.08 & 0.002 & - & 11.31 & 15.33 \\
\hline & 4 & 15.33 & 0.004 & - & 11.52 & 15.82 \\
\hline & 6 & 16.43 & 0.005 & - & 11.71 & 15.96 \\
\hline & 10 & 17.96 & 0.006 & 0.13 & 11.92 & 16.31 \\
\hline & 30 & 19.58 & 0.017 & 0.08 & 12.16 & 16.87 \\
\hline & 50 & 19.81 & 0.028 & 0.06 & 12.23 & 16.99 \\
\hline & 80 & 22.07 & 0.041 & 0.02 & 12.54 & 17.10 \\
\hline & 100 & 22.31 & 0.052 & 0.02 & 12.67 & 17.32 \\
\hline \multirow{8}{*}{0.10} & 2 & 13.57 & 0.003 & - & 11.21 & 15.31 \\
\hline & 4 & 14.79 & 0.005 & - & 11.43 & 15.81 \\
\hline & 6 & 14.98 & 0.006 & - & 11.47 & 15.92 \\
\hline & 10 & 17.13 & 0.008 & 0.12 & 11.82 & 15.29 \\
\hline & 30 & 19.17 & 0.018 & 0.06 & 12.12 & 16.86 \\
\hline & 50 & 19.25 & 0.029 & 0.04 & 12.16 & 16.98 \\
\hline & 80 & 20.56 & 0.043 & 0.03 & 12.41 & 17.08 \\
\hline & 100 & 20.69 & 0.055 & 0.02 & 12.45 & 17.31 \\
\hline \multirow{8}{*}{0.15} & 2 & 13.38 & 0.004 & - & 11.18 & 15.31 \\
\hline & 4 & 14.53 & 0.006 & - & 11.39 & 15.77 \\
\hline & 6 & 14.56 & 0.007 & - & 11.41 & 16.01 \\
\hline & 10 & 16.59 & 0.009 & 0.11 & 11.74 & 16.76 \\
\hline & 30 & 18.22 & 0.021 & 0.04 & 11.99 & 16.97 \\
\hline & 50 & 18.13 & 0.032 & 0.03 & 12.01 & 17.02 \\
\hline & 80 & 19.59 & 0.046 & 0.02 & 12.28 & 17.21 \\
\hline & 100 & 19.67 & 0.059 & 0.02 & 12.38 & 17.29 \\
\hline \multirow{8}{*}{0.20} & 2 & 12.66 & 0.004 & - & 11.04 & 15.31 \\
\hline & 4 & 13.97 & 0.007 & - & 11.29 & 15.74 \\
\hline & 6 & 14.14 & 0.008 & - & 11.33 & 15.99 \\
\hline & 10 & 15.57 & 0.012 & 0.10 & 11.61 & 16.71 \\
\hline & 30 & 17.26 & 0.023 & 0.05 & 11.89 & 16.89 \\
\hline & 50 & 17.09 & 0.034 & 0.03 & 11.92 & 16.98 \\
\hline & 80 & 18.01 & 0.048 & 0.03 & 12.09 & 17.13 \\
\hline & 100 & 18.82 & $0.061 \mid$ & 0.02 & 12.23 & 17.21 \\
\hline
\end{tabular}

\begin{tabular}{|c|c|c|c|c|c|c|}
\hline Formamide & Conc & $\tau / \eta_{\rho}$ & $\phi_{\mu}$ & $\mathrm{V}_{\mathrm{h}}(\mathrm{ml})$ & $\Delta \mathrm{F}_{\tau}$ & $\Delta F_{\eta}$ \\
\hline $\mathrm{M} / \mathrm{l}$ & $\mathrm{mM}$ & ps & & $\mathrm{x} 10^{-20}$ & $\mathrm{~kJ} \mathrm{~mol}^{-1}$ & 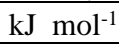 \\
\hline \multirow{8}{*}{0.05} & 2 & 13.99 & 0.002 & - & 11.41 & 15.42 \\
\hline & 4 & 15.07 & 0.004 & - & 11.61 & 15.88 \\
\hline & 6 & 16.19 & 0.005 & - & 11.76 & 15.99 \\
\hline & 10 & 17.54 & 0.007 & 0.36 & 12.02 & 16.38 \\
\hline & 30 & 17.64 & 0.027 & 0.15 & 12.15 & 16.97 \\
\hline & 50 & 18.31 & 0.036 & 0.14 & 12.31 & 17.06 \\
\hline & 80 & 20.61 & 0.043 & 0.09 & 12.64 & 17.14 \\
\hline & 100 & 21.11 & 0.053 & 0.07 & 12.75 & 17.34 \\
\hline \multirow{8}{*}{0.10} & 2 & 13.49 & 0.003 & - & 11.32 & 15.41 \\
\hline & 4 & 14.59 & 0.005 & - & 11.52 & 15.82 \\
\hline & 6 & 14.89 & 0.007 & - & 11.58 & 15.97 \\
\hline & 10 & 16.89 & 0.009 & 0.61 & 11.93 & 16.31 \\
\hline & 30 & 18.08 & 0.028 & 0.20 & 12.21 & 16.92 \\
\hline & 50 & 18.04 & 0.039 & 0.14 & 12.26 & 17.02 \\
\hline & 80 & 19.54 & 0.045 & 0.09 & 12.51 & 17.11 \\
\hline & 100 & 19.46 & 0.056 & 0.09 & 12.55 & 17.31 \\
\hline \multirow{8}{*}{0.15} & 2 & 13.19 & 0.004 & - & 11.26 & 15.37 \\
\hline & 4 & 14.01 & 0.006 & - & 11.41 & 15.78 \\
\hline & 6 & 14.28 & 0.008 & - & 11.48 & 15.91 \\
\hline & 10 & 16.41 & 0.011 & 0.58 & 11.85 & 16.25 \\
\hline & 30 & 17.06 & 0.031 & 0.20 & 12.07 & 16.84 \\
\hline & 50 & 17.11 & 0.042 & 0.14 & 12.09 & 16.89 \\
\hline & 80 & 18.46 & 0.047 & 0.09 & 12.35 & 17.11 \\
\hline & 100 & 19.01 & 0.059 & 0.09 & 12.49 & 17.29 \\
\hline \multirow{8}{*}{0.20} & 2 & 12.51 & 0.005 & - & 11.12 & 15.38 \\
\hline & 4 & 13.83 & 0.008 & - & 11.38 & 15.78 \\
\hline & 6 & 14.02 & 0.009 & - & 11.43 & 15.92 \\
\hline & 10 & 15.45 & 0.013 & 0.60 & 11.71 & 16.28 \\
\hline & 30 & 16.41 & 0.034 & 0.20 & 11.97 & 16.87 \\
\hline & 50 & 16.15 & 0.046 & 0.14 & 11.99 & 16.99 \\
\hline & 80 & 17.12 & 0.049 & 0.09 & 12.17 & 17.11 \\
\hline & 100 & 17.69 & 0.062 & 0.08 & 12.31 & 17.31 \\
\hline
\end{tabular}

\subsection{Micellar SDS solutions.}

The prepared solution range from $2 \mathrm{mM}$ to $100 \mathrm{mM}$ was taken for the present study. The factors responsible for solubilization are the surface between the water and micelle, hydrophilic behavior, palisade layer, and the hydrophobic behavior inside the core $[19,20]$. The dielectric data values are analyzed based on the interaction of additives with the surfactant. The solution behaves as a single relaxation system $\varepsilon^{\prime}$ of the complex dielectric constant as $\varepsilon^{\prime \prime}$, the imaginary part always linked through the following relationship proposed by Cole [21].

$$
\varepsilon^{\prime}=-\tau \omega \varepsilon^{\prime \prime}+\varepsilon_{0}
$$

The straight-line plot obtained between $\varepsilon^{\prime} V s \omega \varepsilon^{\prime \prime}$. The non-linear/random line is obtained for all SDS concentrations and, hence, more than one relaxation mechanism. In the water + amide system, the relaxation and the rating process depend on their concentration [22]. However, the relaxation time having the same increasing trend with the concentration of Nitrile and water molecules. [23], this indicates that the hydrogen bonding environment's inhomogeneity leads to a broad in Cole-Cole function rather than Debye function is evident.

The strong interference between amides molecules and micelles of SDS solutions are observed. The increase of amide concentration decreases the dielectric constant of bulk solutions as 
is expected in a binary amide + water system; rather, the relaxation process seems to be different in other systems. For aqueous SDS solutions, Buchner et al. [24] have confirmed four relaxation times. One of them at $120 \mathrm{ps}(\approx 2 \mathrm{GHz})$ is attributed to the slow water hydration in micellar molecules. The acetamide molecules cannot go into the interior of the micelles. The lower ion-ion concentration disturbing the equilibrium of hydrated water molecules, so the net relaxation times decrease. The shift of this peak is visible at higher concentrations of SDS solution around $3 \mathrm{GHz}$.

$$
\frac{1}{\tau_{\mathrm{obs}}}=\frac{1}{\tau_{1}}+\frac{1}{\tau_{2}}
$$

Where $\tau_{1}$ - is the relaxation time of water molecules around the micelle ions by hydration phenomena, and $\tau_{2}$ - is the relaxation time of micelle inside the micelle by hydrophobic phenomena.

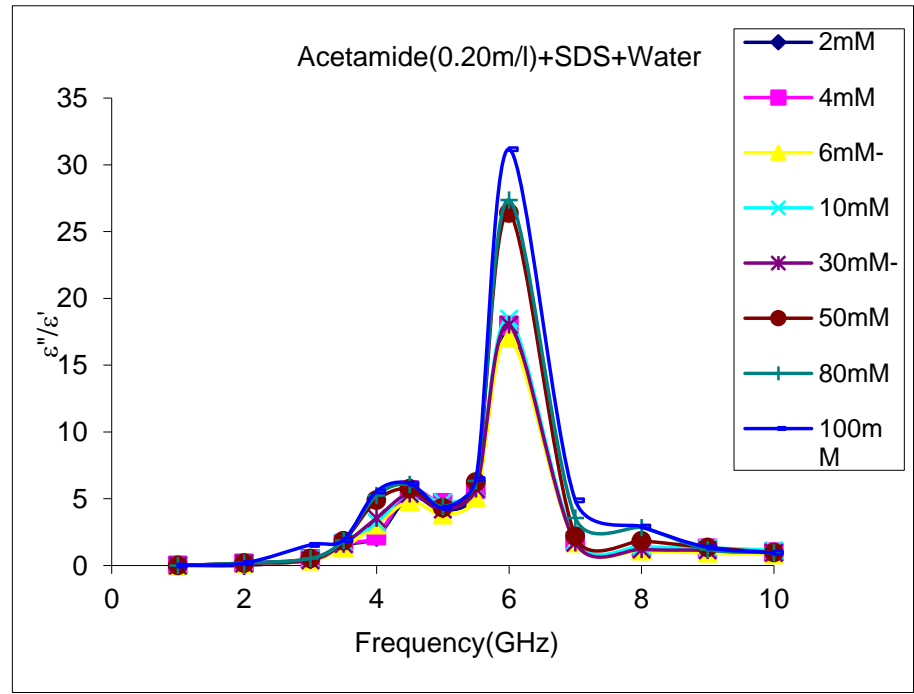

Figure 1. Frequency $V s \varepsilon^{\prime \prime} / \varepsilon^{\prime}$ for different concentrations of acetamide in aqueous SDS.

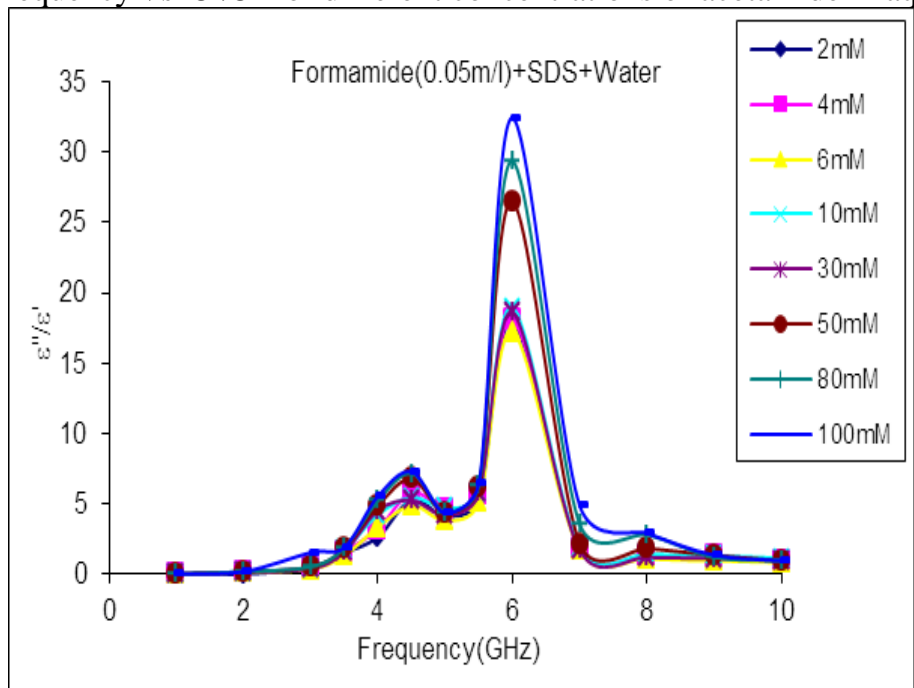

Figure 2. Frequency $V s \varepsilon^{\prime \prime} / \varepsilon^{\prime}$ for different concentrations of formamide in aqueous SDS.

The plot of $\varepsilon^{\prime \prime} / \varepsilon^{\prime} V s$ frequency curve for all the systems investigated is shown in Figure12 , highlights the region $2 \mathrm{GHz}$ to $8 \mathrm{GHz}$. The two distinct peaks one close to $4.5 \mathrm{GHz}$ ( $\tau \approx 35 \mathrm{ps}$ ) and $6.2 \mathrm{GHz}$ ( $\tau \approx 28 \mathrm{ps}$ ). The SDS concentration dependence of the relaxation amplitudes is smooth/flat at the beginning steep and in a higher SDS concentration, showing that there is more hydration of water around SDS micelles. The relaxation amplitude at $35 \mathrm{ps}$ is much 
smaller than 28ps. The CMC is lowered due to the difference in solubilization in water molecules by different additives. Hence below CMC the relaxation times increase rather slowly with a concentration of SDS.

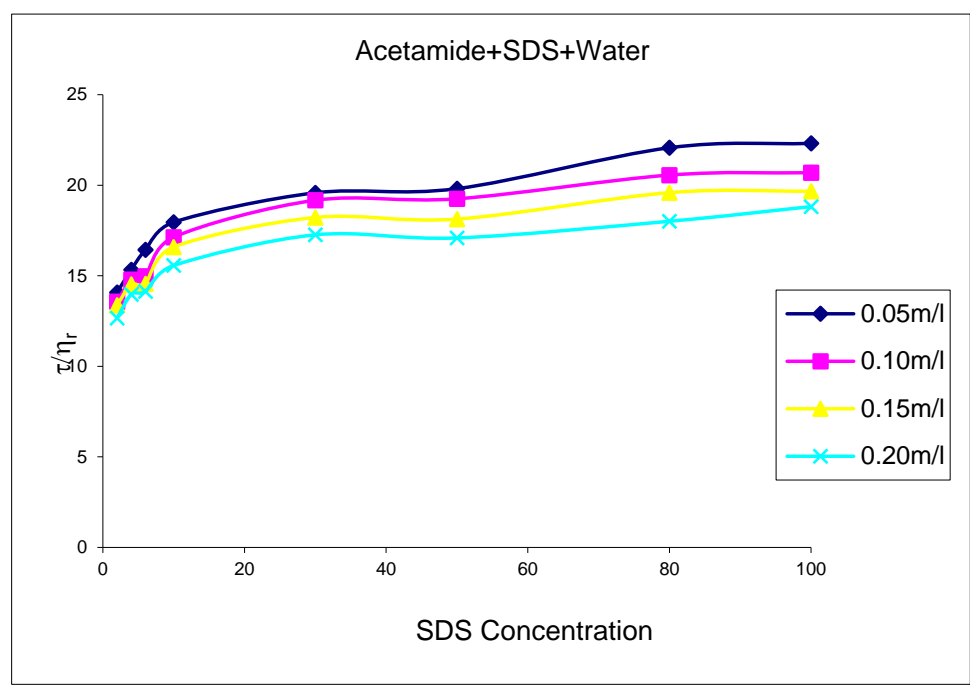

Figure 3. SDS Conc $V s \tau / \eta_{\mathrm{r}}$ for Acetamide in aqueous SDS.

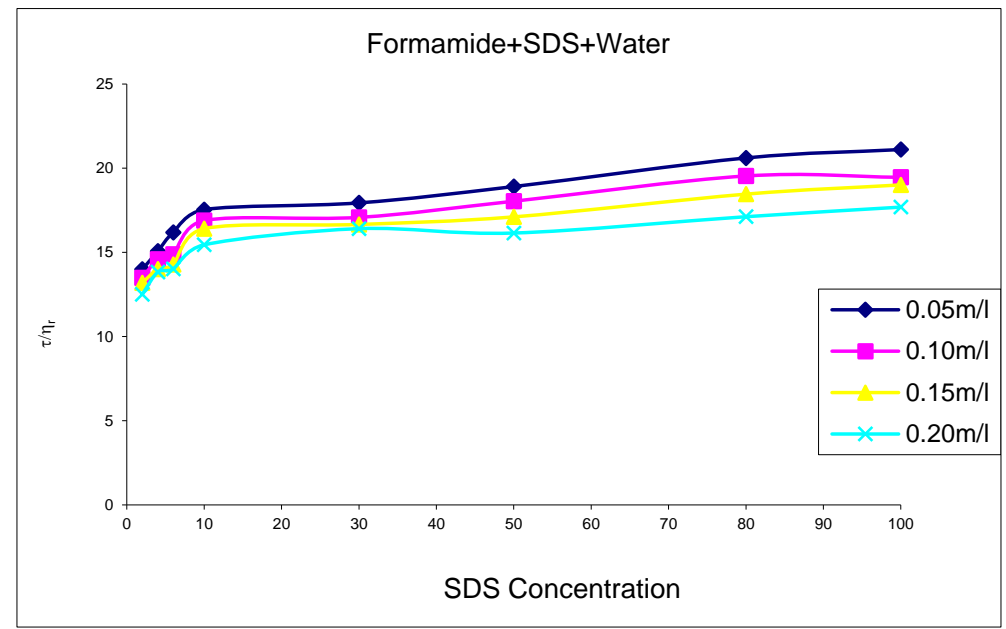

Figure 4. SDS Conc $V s \tau / \eta_{\mathrm{r}}$ for formamide in aqueous SDS.

The viscosity variation depends on the micelle's hydrodynamic volume and its rigidity against the rotational and translational motion. The micelle radius is related to $\tau / \eta_{\mathrm{r}}$ values. Additives like amides and non-polar aliphatic long-chain alkanol solubilize at the site [20]. The compounds chosen in the present study belong to the category of the aliphatic compound. The decreased relaxation time $\tau$ is due to the polar molecules are found in added SDS solutions. The computed values of $\eta$ and $\tau$ are presented in Table 2. A plot of concentration vs. $\tau / \eta_{\mathrm{r}}$ is depicted in Figure (3-4). A small variation was observed at all concentrations of SDS. This indicates that the kinetic equilibrium is disturbed highly at lower concentrations regions.

The free energy of activation of viscous flow $\left(\Delta \mathrm{F}_{\tau}\right)$ is more than that of the free energy of dielectric relaxation time $\left(\Delta \mathrm{F}_{\eta}\right)$. i.e., $\left[\Delta \mathrm{F}_{\tau}>0.5 \Delta \mathrm{F}_{\eta}\right]$. In the first case, the molecules involve only rotational motions, but in the latter case, rotational motions and translation motions and its leads to more interference by neighboring molecule $[17,25]$. 


\section{Conclusions}

The dielectric relaxations studies in SDS with acetamide and formamide are carried out using TDR-time domain reflectometry. From this study, we concluded as free energy activation of viscous flow is predominant over the free energy of dielectric relaxation time. In the larger concentration, the decrement in micellar radius and larger hydrophobic behavior leads to larger values of related dielectric parameters.

\section{Funding}

This research received no external funding.

\section{Acknowledgments}

The authors are very much grateful to the facilities provided by the CSIL, Annamalai University, Annamalainagar, Tamilnadu, India.

\section{Conflicts of Interest}

The authors declare no conflict of interest.

\section{References}

1. Yoshimura, T.; Sakato, A.; Tsuchiya, K.; Ohkubo, T.; Sakai, H.; Abe, M.; Esumi, K. Adsorption and aggregation properties of amino acid-based $\mathrm{N}$-alkyl cysteine monomeric and $\mathrm{N}, \mathrm{N}^{\prime}$-dialkyl cystine gemini surfactants. Journal of Colloid and Interface Science 2007, 308, 466473,https://doi.org/10.1016/j.jcis.2006.11.038.

2. Hunt, N.T.; Turner, A.R.; Tanaka, H.; Wynne, K. The Ultrafast Dynamics of Hydrogen-Bonded Liquids: Molecular Structure-Dependent Occurrence of Normal Arrhenius or Fractional Stokes-Einstein-Debye Rotational Diffusive Relaxation. The Journal of Physical Chemistry B 2007, 111, 9634-9643, https://doi.org/10.1021/jp072409h.

3. Gainaru, C.; Hecksher, T.; Olsen, N.B.; Böhmer, R.; Dyre, J.C. Shear and dielectric responses of propylene carbonate, tripropylene glycol, and a mixture of two secondary amides. The Journal of Chemical Physics 2012, 137,https://doi.org/10.1063/1.4740236.

4. Dong, S.; Li, X.; Xu, G.; Hoffmann, H. A Cationic Fluorocarbon Surfactant DEFUMACl and Its Mixed Systems with Cationic Surfactants: 19F NMR and Surface Tension Study. The Journal of Physical Chemistry B 2007, 111, 5903-5910, https://doi.org/10.1021/jp0705469.

5. Li, G.-L.; Gao, Y.-A.; Li, X.-W.; Liu, J.; Zheng, L.-Q.; Xing, H.; Xiao, J.-X. Aggregation behavior of Nalkyl perfluorooctanesulfonamides in dimethyl sulfoxide solution. Journal of Colloid and Interface Science 2010, 342, 372-381,https://doi.org/10.1016/j.jcis.2009.10.058.

6. Perron, G.; Côté, J.-F.; Lambert, D.; Pageau, J.; Desnoyers, J.E. Volume and heat capacity of model nonaqueous self-assembly systems. Journal of Solution Chemistry 1994, 23, 121-133, https://doi.org/10.1007/BF00973541.

7. Hetu, D.; Camire, C.; Perron, G.; Desnoyers, J.E. Volume and Heat Capacity of n-Pentanol in Aqueous Surfactants: Effect of Chain Length and Polarity of the Head Group. Langmuir 1994, 10, 4039-4047, https://doi.org/10.1021/la00023a023.

8. Wettig, S.D.; Verrall, R.E. Thermodynamic Studies of Aqueous m-s-m Gemini Surfactant Systems. Journal of Colloid and Interface Science 2001, 235, 310-316,https://doi.org/10.1006/jcis.2000.7348.

9. Desnoyers, J.E.; Perron, G.; Birdi, K.S. (Ed.). Handbook of Surface and Colloid Chemistry. CRC Press, Boca Raton, FL, 1997; pp. 119-145.

10. Desnoyers, J.E; Perron, G; Roux, AH; Zana, R. Surfactant Solutions New Methods of Investigation. Marcel, D. New York, 1986; pp. 22-46.

11. Lou, N.; Wang, Y.; Li, X.; Li, H.; Wang, P.; Wesdemiotis, C.; Sokolov, A.P.; Xiong, H. Dielectric Relaxation and Rheological Behavior of Supramolecular Polymeric Liquid. Macromolecules 2013, 46, 3160-3166, https://doi.org/10.1021/ma400088w.

12. Wang, Y.; Griffin, P.J.; Holt, A.; Fan, F.; Sokolov, A.P. Observation of the slow, Debye-like relaxation in hydrogen-bonded liquids by dynamic light scattering. The Journal of Chemical Physics 2014, 140, https://doi.org/10.1063/1.4867913. 
13. Rander, D.N.; Joshi, Y.S.; Kanse, K.S.; Kumbharkhane, A.C. Thermodynamic and dielectric relaxation study of erythritol-water binary mixture using time domain reflectometry. Journal of Molecular Liquids 2014, 199, 367-370, https://doi.org/10.1016/j.molliq.2014.09.037.

14. Shirgire, S.D.; Talware, R.B.; Kadam, S.S.; Kumbharkhane, A.C. Dielectric relaxation of d-sorbitol-water mixtures using a Time Domain Reflectometry Technique. Journal of Molecular Liquids 2012, 169, 33-36, https://doi.org/10.1016/j.molliq.2012.03.001.

15. Turton, D.A.; Wynne, K. Structural relaxation in the hydrogen-bonding liquids N-methylacetamide and water studied by optical Kerr effect spectroscopy. J Chem Phys 2008, 128, https://doi.org/10.1063/1.2897432.

16. Bevington, P.R.; Robinson, D.K.; Blair, J.M.; Mallinckrodt, A.J.; McKay, S. Data Reduction and Error Analysis for the Physical Sciences. Computers in Physics 1993, 7, 415-416, https://doi.org/10.1063/1.4823194.

17. Ganesh, T.; Sabesan, R.; Krishnan, S. Dielectric relaxation spectroscopic studies of ionic surfactants in aqueous solutions. Journal of Molecular Liquids 2006, 128, 77-80, https://doi.org/10.1016/j.molliq.2005.11.038.

18. Gainaru, C.; Figuli, R.; Hecksher, T.; Jakobsen, B.; Dyre, J.C.; Wilhelm, M.; Böhmer, R. Shear-Modulus Investigations of Monohydroxy Alcohols: Evidence for a Short-Chain-Polymer Rheological Response. Physical Review Letters 2014, 112, https://doi.org/10.1103/PhysRevLett.112.098301.

19. Joshi, Y.S.; Shinde, J.B.; Rander, D.N.; Kanse, K.S.; Kumbharkhane, A.C. Dielectric dispersion study of binary mixtures of methyl ethers with water at $298.15 \mathrm{~K}$ using frequency domain technique.Indian Journal of Pure \& Applied Physics 2020, 58, 448-454.

20. Hefter, G.; Buchner, R. Dielectric relaxation spectroscopy: an old-but-new technique for the investigation of electrolyte solutions. Pure and Applied Chemistry 2020, 92, 1595-1609, https://doi.org/10.1515/pac-20191011.

21. Cole, R.H. On the Analysis of Dielectric Relaxation Measurements. The Journal of Chemical Physics $\mathbf{1 9 5 5 ,}$ 23, 493-499,https://doi.org/10.1063/1.1742017.

22. Mathpati, R.N.; Hudge, P.G.; Kanse, K.S.; Joshi, Y.S.; Kumbharkhane, A.C. Dielectric relaxation and hydrogen bonding interaction of polyethylene glycol dimethyl ether in water mixture. Physics and Chemistry of Liquids 2020, 58, 664-674, https://doi.org/10.1080/00319104.2019.1633527.

23. Sperl, M. Cole-Cole law for critical dynamics in glass-forming liquids. Physical Review E 2006, 74, https://doi.org/10.1103/PhysRevE.74.011503.

24. Kalaivani, T.; Krishnan, S.; Nithiyanantham, S. Physico-chemical and dielectric relaxation studies of ionic surfactants in Time Domain Reflectometry (TDR). Korean Journal of Chemical Engineering 2017, 34, 2325-2330, https://doi.org/10.1007/s11814-017-0138-6.

25. Kalaivani, T.; Undre, P.; Sabesan, R.; Krishnan, S. Dielectric relaxation studies of nitriles solubilized by Sodium dodecyl sulphate in aqueous solutions.Journal Molecular Liquids2012, 172, 76-80, https://doi.org/10.1016/j.molliq.2011.11.018. 